\title{
Limits of the social-benefit motive among high-risk patients: a field experiment on influenza vaccination behaviour
}

\author{
Ozan Isler ${ }^{1,2}$, Burcu Isler ${ }^{3,4}$, Orestis Kopsacheilis ${ }^{2,5^{*}}$ and Eamonn Ferguson ${ }^{6^{*}}$ (D)
}

\begin{abstract}
Background: Influenza vaccine uptake remains low worldwide, inflicting substantial costs to public health. Messages promoting social welfare have been shown to increase vaccination intentions, and it has been recommended that health professionals communicate the socially beneficial aspects of vaccination. We provide the first test whether this prosocial vaccination hypothesis applies to actual vaccination behaviour of high-risk patients.

Methods: In a field experiment at a tertiary care public hospital in Istanbul, Turkey, we compare the effects of two motivational messages for promoting vaccination. Using a between-subjects single-blind experimental design patients were randomly assigned to frames emphasizing the vaccine's benefits to self $(n=125)$ or social benefits $(n=119)$. Free influenza vaccination was offered to each patient.
\end{abstract}

Results: Among 222 patients who were not vaccinated for the season prior to the study (72\% medically assessed to be at high risk), $42 \%$ in the self-benefit frame chose to receive a vaccination compared with $34 \%$ in the socialbenefits frame, but the difference was not statistically significant ( $a \mathrm{OR}=1.63,95 \% \mathrm{Cl} 0.90$ to $2.95, p=0.108$ ). Reasons for vaccination focused primarily on self-benefit (67\%) rather than social-benefit (5\%). Exploratory analysis showed that the effect of messages depended on patient perception of risk group membership $\left(\mathrm{aOR}_{\text {High }} / \mathrm{aOR}\right.$ Low $=5.59$, $95 \% \mathrm{Cl} 1.30$ to $24.05, p=0.021$ ). In particular, emphasis on self-benefit was more influential among patients who perceived themselves to be in the risk group ( $\mathrm{aOR}=6.22,95 \% \mathrm{Cl} 1.69$ to $22.88, p=0.006$ ).

Conclusions: In contrast to the literature observing intentions of low-risk populations, we found no evidence that social-benefit motivates actual vaccination behaviour among a high-risk patient population. Instead, those who selfcategorize as being in the high risk group are more motivated by the self-benefit message. Our results suggest that a stratified approach can improve coverage: even if an emphasis on social-benefit could be effective among lowrisk groups, an emphasis on self-benefit holds more promise for increasing vaccination in medical organizational settings where high-risk groups are prevalent.

Trial registration: ClinicalTrials.gov NCT04230343 Retrospectively registered on the 13th January 2020.

Keywords: Vaccination, Influenza, Field experiment, Social benefit, Risk group, Risk perceptions, Framing, Nudge

\footnotetext{
*Correspondence: orestis.kopsacheilis@nottingham.ac.uk;

eamonn.ferguson@nottingham.ac.uk

${ }^{2}$ Centre for Decision Research and Experimental Economics (CeDEx),

University of Nottingham, Nottingham, UK

${ }^{6}$ School of Psychology, University of Nottingham, Nottingham NG7 2RD, UK

Full list of author information is available at the end of the article
}

C The Author(s). 2020 Open Access This article is distributed under the terms of the Creative Commons Attribution 4.0 International License (http://creativecommons.org/licenses/by/4.0/), which permits unrestricted use, distribution, and reproduction in any medium, provided you give appropriate credit to the original author(s) and the source, provide a link to the Creative Commons license, and indicate if changes were made. The Creative Commons Public Domain Dedication waiver (http://creativecommons.org/publicdomain/zero/1.0/) applies to the data made available in this article, unless otherwise stated. 


\section{Background}

Influenza poses a serious threat to human health, annually resulting in 250,000 to 500,000 deaths worldwide [1]. Even though the influenza vaccine is widely available and affordable, its global uptake remains low [2]. Meanwhile, the negative impact of influenza is expected to grow due to rapid increases in high-risk populations such as the elderly [3]. As long as herd immunity remains a distant goal, vaccination of high-risk populations will remain a public health priority [4], despite vaccination's limited effectiveness in such populations [5]. Furthermore, even with accrued knowledge of the social and psychological correlates of vaccination $[3,6-8]$, causal pathways that can be exploited to increase uptake remain poorly understood, rendering the behavioural impact of public policies ambiguous. In particular, experimental investigations of vaccination behaviour among high-risk patient groups are rare. Our study hence focuses on behavioural interventions to motivate vaccination among those at heightened risk of harm from influenza infection.

A promising candidate for promoting vaccination is the idea of harnessing prosocial motives (e.g., care for family, friends and community) by highlighting the social benefits of vaccination [9]. Various studies report evidence that messages about the social benefits of vaccination strengthen the intentions to vaccinate [10-12]. Based on these findings, it was recently recommended that professionals can increase vaccine uptake by emphasizing its social benefits [13]. We refer to this view as the prosocial vaccination hypothesis. Given accumulated evidence for the prevalence of prosocial motives in other domains $[14,15]$, the idea is promising. However, evidence for the prosocial vaccination hypothesis remains limited for two reasons.

First, the general applicability of the prosocial vaccination hypothesis is not well-established. In particular, the effects of health behaviour interventions will likely depend on psychological differences [7, 16, 17] such as risk perceptions [18-21]. Supporting this view, prosocial sensitivities have been found to decrease with disease risk [22], and the effect of motivational messages have been found to depend on the relative prevalence of high and low risk groups [23].

Second, most experiments investigating social benefit as a vaccination motive measured intentions among lowrisk populations in artificial settings [9, 11, 12, 22, 23]. However, intentions do not always predict behaviour well [24-26]. In particular, hypothetical scenarios may enhance a preference to appear altruistic [27, 28] and thus limit generalizability of previous evidence [29, 30]. The only two field experiments testing the hypothesis found no advantage of prosocial messages in promoting vaccination, yet they studied the behaviour of health- care professionals and not the more prevalent patient groups $[31,32]$. It hence remains unknown whether social welfare motivates actual vaccination uptake of highrisk groups in real-world settings [9].

To overcome these two limitations, we conducted the first field experiment in a hospital setting that observed the causal effects of prosocial messages on the vaccination behaviour of high-risk patients in a natural environment. We used two motivational frame manipulations, one emphasizing the self-benefit and the other emphasizing the social-benefit of vaccination. The two frames used in our experiment were based on actual vaccine promotion pamphlets employed by the UK National Health Service. The prosocial vaccination hypothesis predicts that emphasizing the social benefits of vaccination will increase uptake compared to an emphasis only on benefits to self.

Perceived risk has been shown to be a more powerful predictor of vaccination than objective risk [33]. We compare objective (medically diagnosed) and subjective (patient perceived) measures of risk group status, indicating high or low risk of severe harm due to influenza related illnesses [8], and explore whether they moderate the effect of prosocial messages on vaccination behaviour. We provide self-reported reasons for vaccine acceptance and refusal as well as a rationale why socialbenefit messages may be counterproductive for those who perceive themselves as being in the risk group for influenza complications.

\section{Methods}

\section{Participants}

Participants were recruited at a tertiary care public hospital in Istanbul from November 2016 to March 2017. Two hundred and fifty-one adult patients were approached during the twenty-week study period and 244 of them (97\%) agreed to participate. One hundred and sixteen patients were female $(48 \%)$, the median age was 60 and only 54 patients had education levels higher than primary school (22\%). Patients were recruited from the Internal Medicine (41\%), Neurology (28\%), Infectious Diseases (23\%), Physical Medicine (7\%) and Dermatology (1\%) wards. Eighty-six participants were diagnosed with an infectious disease at admission to the hospital (35\%). The two most common infection diagnoses were pneumonia (42\%) and urinary tract infections (17\%). Other diagnoses of infections included skin and soft tissue infections, intra-abdominal infections, viral hepatitis, central nervous system infections, HIV infection, etc. Patients were randomly assigned to either the selfbenefit or the social-benefit message. Twenty-two of the 244 patients $(9 \%)$ reported that they were already vaccinated for the season (see Fig. 1 \& Table 1). 


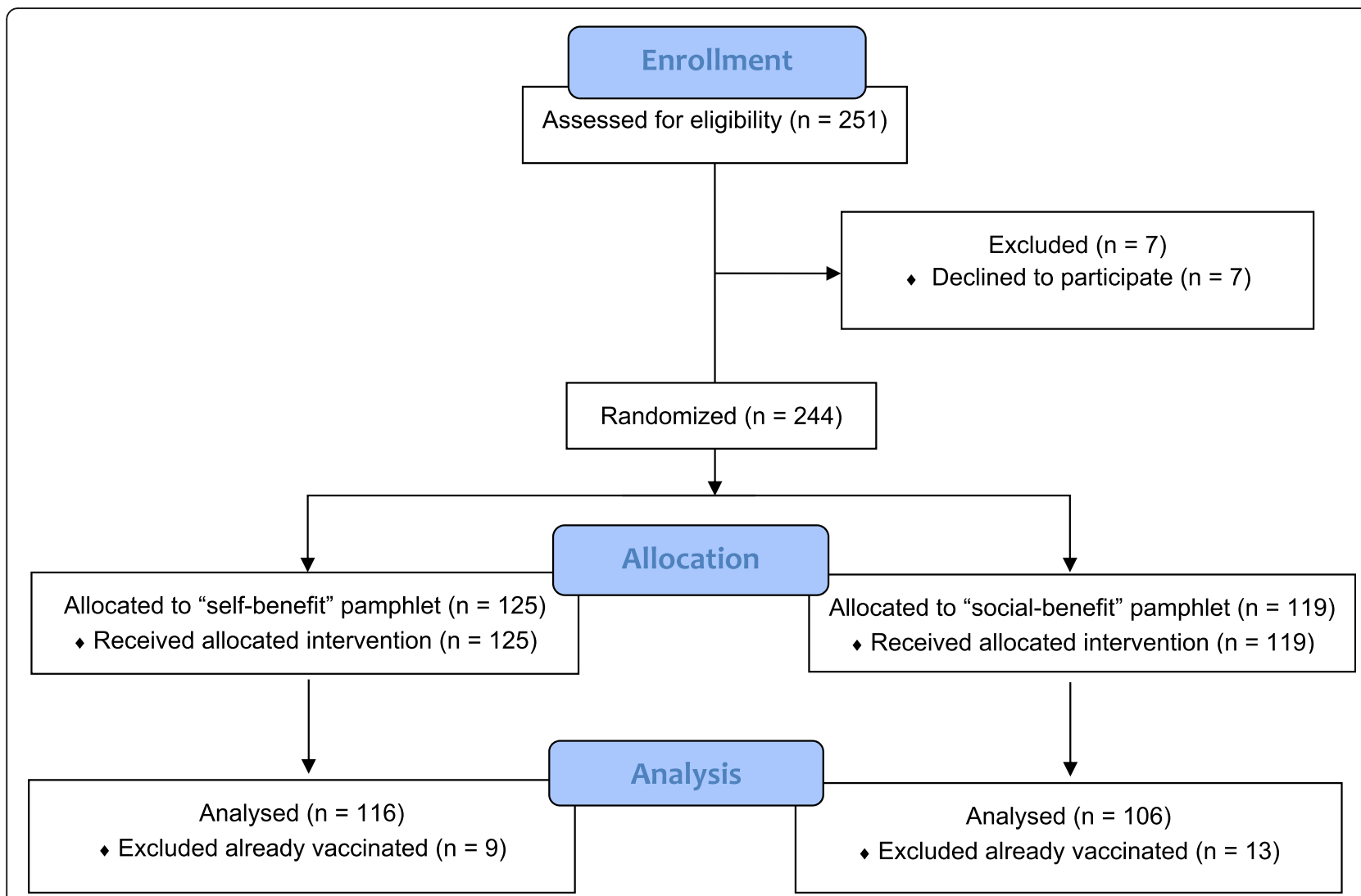

Fig. 1 Study flow

\section{Power calculations}

Because there is no previous comparison of the effects of self- and social-benefit on actual patient vaccination behaviour, we assumed a medium effect size $(\mathrm{aOR}=3.0$ or a Cohen's $d$ of 0.60$)[34,35]$. This value is smaller than the previously found effect $(d=0.74)$ of communicating social benefit when individual benefit was already conveyed and when vaccination was immediately accessible [10], as was the case in our study. We planned for a two-tailed logistic model $(\alpha=0.05 \& 1-\beta=0.80)$ and aimed to recruit a total of 159 objectively high-risk patients, not yet vaccinated for the flu season, for the two treatment groups. Until we reached our high-risk patient target, we also recruited low-risk patients, who were less prevalent among hospital in-patients. We consequently recruited 159 objectively assessed high-risk and 63 lowrisk patients who were not yet vaccinated for the flu season as well as 22 patients who were already vaccinated for the season.

\section{Procedure}

One of the researchers, an infectious disease physician, recruited in-patients on the day of their discharge. By selecting the next pamphlet on the top of a previously shuffled stack, patients were randomly assigned to one of two treatment groups, including either the self-benefit (51\%) or the social-benefit message treatment (49\%). The pamphlets were modelled after actual vaccine promotion messages used by NHS Wales. ${ }^{1}$ Each treatment consisted of short text and an abstract figure, facilitating the transparency of the message to a relatively old and poorly educated participant pool (see Fig. 2). The top halves of the two pamphlets were the same and described the official criteria for qualifying to be in the risk group (Fig. 2a). At the bottom half, the text in the selfbenefit treatment indicated that one can gain immunity against influenza by getting the vaccine (Fig. 2b), while the text in the social-benefit treatment in addition stated that gaining immunity would lower the chances of transmitting the disease to others (Fig. 2c). Prompts of "protect yourself" vs. "protect those around you" and corresponding emoticons were added to increase the salience and the clarity of each message [36-38]. Consistent with the pamphlets used by NHS Wales, no explanation of herd immunity was provided, and both pamphlets listed the objective risk group criteria and

\footnotetext{
${ }^{1}$ The pamphlet is publicly available at https://www.nhsdirect.wales.nhs. uk/pdfs/Main\%20Flu\%20Poster\%20WEB.pdf
} 
Table 1 Characteristics of participants in analysis across the treatment arms $(n=222)$

\begin{tabular}{lllc}
\hline & Social-benefit & Self-benefit & $p$-value* \\
\hline Age, median years (mean \pm SD) & $59(57 \pm 17)$ & $60(56 \pm 18)$ & 0.68 \\
Gender & & & \\
Female & $47(44)$ & $59(56)$ & 0.33 \\
Male & $59(51)$ & $57(49)$ & \\
Diagnosis at admission & & & \\
Infectious disease & $32(41)$ & $47(59)$ & 0.11 \\
Other diagnosis & $74(52)$ & $69(48)$ & \\
Ward & & & \\
Infectious Diseases & $22(42)$ & $31(58)$ & 0.57 \\
Internal Medicine & $46(53)$ & $41(47)$ & \\
Neurology & $31(48)$ & $34(52)$ & \\
Other & $7(41)$ & $10(59)$ & \\
Education & & & \\
Less than high school degree & $81(47)$ & $93(53)$ & 0.50 \\
High school degree or above & $25(52)$ & $23(48)$ & \\
Objective risk group (medical assessment) & & \\
High & $77(48)$ & $82(52)$ & 0.75 \\
Low & $29(46)$ & $34(54)$ & \\
Subjective risk group (patient perception) & & \\
High & $26(51)$ & $25(49)$ & \\
Low & $80(47)$ & $91(53)$ & \\
\hline
\end{tabular}

Note. Number of persons (\%), unless otherwise indicated. ${ }^{*} t$-test for age, $x^{2}$ otherwise

stated that influenza can have serious complications especially for someone in the risk group.

The pamphlets were given after eliciting written informed consent and between two questionnaires that sought basic demographic information as well as knowledge, experience, attitudes and perceptions regarding influenza and its vaccine (see Additional file 1 for the questionnaires). Care was taken to limit any further verbal interaction between the researcher and the patients. We allowed only two types of patient requests to change the course of the interaction. First, the researcher uniformly recommended the vaccine only if asked for her advice (30\%). Second, the researcher read out the pamphlet when help was requested $(55 \%)$ or otherwise left the room for $5 \mathrm{~min}$. Assistance for reading was sought primarily due to old age and illiteracy. In these cases, information flow on the pamphlets was used as the script. The binary variables of asking for recommendation (Self-benefit: 29\%; Social-benefit: 30\%) and asking for help with reading (Self-benefit: 57\%; Social-benefit: $52 \%)$ did not systematically differ between the two treatment conditions.

Upon the researcher's return to the room and prior to the second questionnaire, the decision of whether or not to get the freely provided flu vaccine was elicited. Participants who decided to receive the free vaccine were vaccinated on site at the end of the study, which comprised the primary outcome measure.

After the elicitation of vaccination decision, as part of the second questionnaire (see Additional file 1: Table S1), reasons for accepting or refusing vaccination as well as perceptions for being in the high riskgroup (i.e., subjective risk) were measured by asking "Why do you [not] want to get vaccinated?" (Q2.1) and "Are you in the risk group for flu?" (Q2.2). In contrast, patients were categorized as at high objective risk through medical assessment based on the criteria set out by the Turkish Ministry of Health at the time of the study and listed on the pamphlets for defining high-risk of mortality due to influenza-related illnesses: elderly $(\geq 65)$, people with various chronic illnesses (e.g., diabetes, asthma). Those who did not belong to any of these groups formed the low objective risk group.

As a secondary outcome measure, all participants were finally given a free vaccination ticket that could be used by patient's family and friends within 2 weeks. This was intended to explore whether social networks can boost vaccination beyond the hospital setting. Since information on the tickets was provided after elicitation of vaccination decisions (as well as after the questionnaires), this additional feature could not influence the primary outcome measure.

\section{Analysis}

Twenty-two of the 244 patients $(9 \%)$ have indicated in the questionnaires that they were already vaccinated for the season. Hence, we restricted our analysis of treatment effects to the 222 patients who were not yet vaccinated ( $74 \%$ medically assessed to be at high risk) and who randomly received either the self-benefit $(52 \%)$ or the social-benefit (48\%) treatment.

We recorded the two types of endogenous variation in interventions-patients asking for recommendation and patients asking for the pamphlet to be read out loud for them-and we control for them as covariates in our analysis. First, we estimated a simple logistic regression to find the effect of the prosocial message on vaccination (Model A). Next, we estimated the moderation of the treatment effect by objective risk in a logistic model that includes the experimental treatment, objective risk group status and their interaction (Model B). Using a similar interaction model, we then explored the moderation of the treatment effect by perceived risk-group membership (Model C). To ensure that any effect we observe is not due to the inclusion of the two aforementioned covariates [39], we ran these models twice, once 
(a) Risk group information

\section{Free Flu Vaccination Information Form}

1) Are you 65 or over?

2) Do you have diabetes, asthma, blood disorders, chronic heart or chronic lung disease?

3) Do you have any immune suppressive diseases?

If you answer yes to at least one of these three questions, then you are in the risk group. Diseases due to flu such as pneumonia may be deadly, especially for the risk group.

\section{(b) Self-benefit frame}

By getting the flu vaccine you can gain immunity against flu.

Protect Yourself!

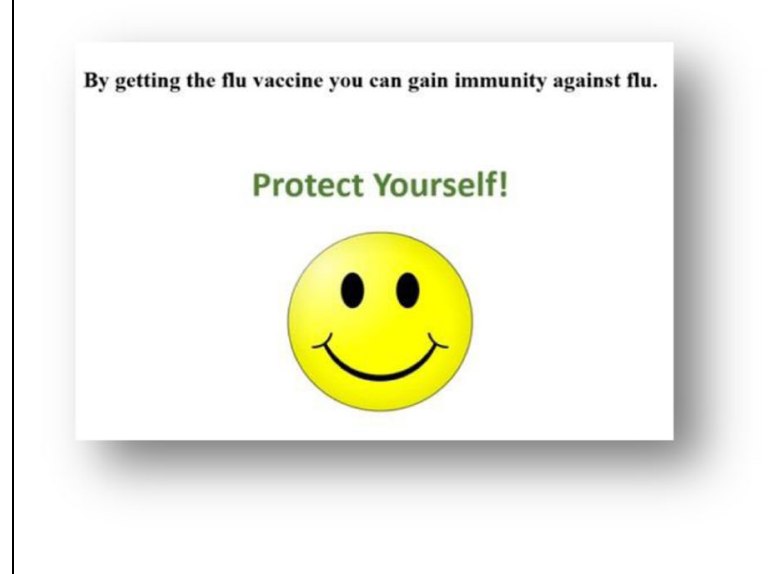

(c) Social-benefit frame

By getting the flu vaceine you can gain immunity against flu. You will thus lower the odds of transmitting flu to others around you. Protect Those Around You!

Fig. 2 Experimental Treatments

with (the adjusted models) and a second time without the covariates (the unadjusted models).

Finally, we summarized reasons provided for vaccine acceptance and refusal, examined the overall impact of the intervention on vaccine uptake, and described the outcome of the free vaccine ticket program.

\section{Results}

Among the 222 patients in the analysis, 159 were medically assessed to be in the high risk group (72\%), whereas only 51 of 222 patients perceived themselves at high risk (23\%). One hundred and twenty-eight of 222 patients (58\%) miscategorized their risk group status. Among these patients with inaccurate risk perceptions, 118 underestimated their risk (92\%) as compared to $10 \mathrm{pa-}$ tients who overestimated their risk (8\%).

We find no evidence that an emphasis on the vaccination's social-benefits increases vaccination as compared to an emphasis on its self-benefit. In fact, as shown in Model A in Table 2, vaccination uptake in the selfbenefit treatment was 8 percentage points higher than in the social-benefit treatment. However, this difference was not statistically significant $(\mathrm{aOR}=1.63,95 \% \mathrm{CI} 0.90$ to $2.95, p=0.108$ ). As shown in Model B on Table 2, the difference in vaccination rates between the two treatment groups also did not depend on whether patients were medically assessed to be at high or low risk of influenza-related complications $\left(\mathrm{aOR}_{\mathrm{High}} / \mathrm{aOR}_{\mathrm{Low}}=\right.$ $0.88,95 \%$ CI 0.22 to $3.55, p=0.856$ ).

As shown in Model C on Table 2, exploratory analysis of perceived risk group status showed a significant moderation of the treatment effect among the overall sample $\left(\mathrm{aOR}_{\mathrm{High}} / \mathrm{aOR}\right.$ Low $=5.59,95 \%$ CI 1.30 to $24.05, p=0.021)$. Specifically, the self-benefit message significantly increased vaccination more than the social-benefit message among those who perceived themselves as being in the high risk group $(\mathrm{aOR}=$ $6.22,95 \%$ CI 1.69 to $22.88, p=0.006$ ) while it had no additional effect on vaccination among those who perceived themselves as being in the low risk group $(\mathrm{aOR}=1.11,95 \%$ CI 0.56 to $2.20, p=0.758)$. As seen in the unadjusted estimates columns on Table 2, these results are robust to the exclusion of the two covariates [39]. 
Table 2 Effect of frames on vaccination and its moderation by objective and subjective risk group

\begin{tabular}{|c|c|c|c|c|c|}
\hline \multirow[t]{3}{*}{ Determinant } & \multirow{3}{*}{$\begin{array}{l}\text { Vaccinated } \\
\text { patients / } \\
\text { Patients in } \\
\text { category (\%) }\end{array}$} & \multicolumn{2}{|c|}{ Adjusted } & \multicolumn{2}{|c|}{ Unadjusted } \\
\hline & & Subgroup & Interaction & Subgroup & Interaction \\
\hline & & $\mathrm{aOR}[95 \% \mathrm{Cl}]$ & $\mathrm{aOR}_{\text {High }} / \mathrm{aOR}$ Low $[95 \% \mathrm{Cl}]$ & OR $[95 \% \mathrm{Cl}]$ & $\mathrm{OR}_{\text {High }} / \mathrm{OR}_{\text {Low }}[95 \% \mathrm{Cl}]$ \\
\hline \multicolumn{6}{|c|}{ Model A: Overall Effects of Frames } \\
\hline Social-benefit & $36 / 106(34.0)$ & 1 & & 1 & \\
\hline Self-benefit & $49 / 116(42.2)$ & $1.63[0.90-2.95]$ & & $1.42[0.82-2.46]$ & \\
\hline \multicolumn{6}{|c|}{ Model B: Moderation of framing effects by objective risk (medical assessment) } \\
\hline Low Risk Group & $15 / 63(23.8)$ & & & & \\
\hline Social-benefit & $6 / 29(20.7)$ & 1 & \multirow{2}{*}{1} & 1 & \multirow{2}{*}{1} \\
\hline Self-benefit & $9 / 34(26.5)$ & $1.82[0.53-6.17]$ & & $1.38[0.42-4.49]$ & \\
\hline High Risk Group & $70 / 159(44.0)$ & & & & \\
\hline Social-benefit & $30 / 77(39.0)$ & 1 & \multirow{2}{*}{$0.88[0.22-3.55]$} & 1 & \multirow{2}{*}{$1.08[0.28-4.13]$} \\
\hline Self-benefit & $40 / 82(48.8)$ & $1.60[0.80-3.17]$ & & $1.49[0.79-2.81]$ & \\
\hline \multicolumn{6}{|c|}{ Model C: Moderation of framing effects by subjective risk (patient perception) } \\
\hline Low Risk Group & $62 / 171(36.3)$ & & & & \multirow{3}{*}{1} \\
\hline Social-benefit & $29 / 80(36.3)$ & 1 & \multirow{2}{*}{1} & 1 & \\
\hline Self-benefit & $33 / 91(36.3)$ & $1.11[0.56-2.20]$ & & $1.00[0.53-1.87]$ & \\
\hline High Risk Group & $23 / 51(45.1)$ & & & & \\
\hline Social-benefit & $7 / 26(26.9)$ & 1 & \multirow{2}{*}{5.59 [1.30-24.05] } & 1 & \multirow{2}{*}{4.82 [1.25-18.56] } \\
\hline Self-benefit & $16 / 25(64.0)$ & $6.22[1.69-22.88]$ & & $4.83[1.46-15.92]$ & \\
\hline
\end{tabular}

Note. Table presents vaccination rates and describes corresponding logistic model estimates for three models. Model A describes the overall effect of message frame treatment on vaccination. Model $\mathrm{B}$ describes the interaction between objective risk and treatment, whereas Model $\mathrm{C}$ describes the interaction between subjective risk and treatment. Adjusted estimates include two covariates: doctor's recommendation and reading of the pamphlet. Unadjusted estimates provide consistent results. Robust SE. $p<0.05$ in bold

Among 72 patients who sought and received the doctor's recommendation, 47 chose to receive vaccination (65.3\%), in comparison to 38 of $150(25.3 \%)$ patients who did not seek recommendation. This covariate was significant in all three models (Model A: $\mathrm{aOR}=5.52$, 95\% CI 2.94 to $10.35, p<0.001)$. Help with reading of the pamphlet was sought by 117 patients, 51 of whom vaccinated (43.6\%). Among the 105 patients who did not seek such help, 34 vaccinated (32.4\%). This covariate was not significant in any of the three models (Model A: $\mathrm{aOR}=1.30,95 \%$ CI 0.71 to $2.38, p=0.394$ ).

Patients $(n=222)$ were asked to provide reasons for their vaccination decisions, and answers were categorized as belonging to one of five acceptance or one of five refusal reason types (See Table 3). Two coders (OI \& BI) independently assigned each answer to one reason

Table 3 Reasons for vaccine acceptance \& refusal

\begin{tabular}{llll}
\hline Acceptance $(n=85)$ & & Refusal $(n=137)$ \\
\hline Self-protection & $57(67.1 \%)$ & Self-confidence & $36(26.3 \%)$ \\
Recommendation & $7(8.2 \%)$ & Current-conditions & $36(26.3 \%)$ \\
Others'-protection* & $4(4.7 \%)$ & Vaccine mistrust & $21(15.3 \%)$ \\
Being in risk group & $3(3.5 \%)$ & Inexperience & $19(13.9 \%)$ \\
Other or no reason & $14(16.5 \%)$ & Other or no reason & $25(18.3 \%)$ \\
\hline
\end{tabular}

* Including "protection of self and others" type (Cohen's kappa: 0.811 for vaccinated \& 0.766 for refused). Given the high inter-rater reliability, any discrepancies in ratings were resolved by mutual agreement. Among those who decided to receive the vaccine as part of the study, the overwhelming majority cited "self-protection" as the reason (67\%), whereas only four patients referred to protection of others (5\%). Among those who decided not to receive the vaccine, responses that reflected confidence in one's current health status such as "I am healthy", "I don't need vaccines", and "I never catch the flu" were categorized as "self-confident". The most common reasons for rejection were found to be "self-confidence" (26\%), "current health conditions" such as receiving other treatments (26\%), "vaccine mistrust" (15\%) and "lack of experience or knowledge regarding the vaccine" (14\%). Although "self-protection" was a more prevalent reason in the self-benefit $(61 \%)$ than in the social-benefit treatment (39\%), no statistically significant difference due to experimental manipulations was observed for any category in either acceptance or refusal reasons (Fisher's exact tests: $p=0.423$ and $p=0.738$ respectively).

As a consequence of our intervention, 85 of 222 (38\%) patients who were not yet vaccinated for the flu season chose to receive vaccination. Including the 22 participants who were already vaccinated at the start of the 
study, rate of vaccination by the end of the study was $44 \%$. These values indicate substantial improvements over previous year rate of $16 \%$ vaccination among all 244 study participants (based on questionnaire item Q1.7, see SI) as well as over the 2006 vaccination rates of $6-19 \%$ among high-risk groups in Turkey [40].

None of the 244 free vaccination tickets were brought back to the hospital to receive free vaccination. Though we have no way of knowing, we conjecture that patients either failed to pass the tickets on to others or when they did, they failed to persuade others to vaccinate. Either of these cases can be interpreted as evidence against strong prosocial motives in vaccination among a high-risk group.

\section{Discussion}

\section{Principle findings}

This field experiment provides the first behavioural test of the prosocial vaccination hypothesis among a predominantly high-risk patient population. This hypothesis builds on tests of vaccination intentions in hypothetical scenarios [10-12], as well as on domain-general evidence that people care about the well-being of others $[14,15]$. However, evidence suggests that an emphasis on social-benefits may not be as effective in a high-risk group. Indeed, direct self-benefit motives are often relatively stronger than social-benefit motives, especially when people feel personally at risk [22, 23]. Moreover, no previous study has provided decisive evidence from the field that prosocial messages increase vaccination coverage [9], and it has been suggested that an emphasis on self-protection may be more successful in increasing vaccination than an emphasis on its social benefits [32].

We compared the effectiveness of two alternative messages for motivating vaccination among a high-risk group facing real stakes. Failing to provide evidence for the prosocial vaccination hypothesis, the social-benefit message was not found to increase vaccination as compared to the self-benefit message. Although the difference was not statistically significant, average vaccination rate was 8 percentage points higher among those who received the self-benefit message than those who received the social-benefit message.

Furthermore, through our exploratory analysis, we found the self-benefit message to be significantly more effective among patients who perceived themselves to be in the high risk group. This is consistent with both empirical evidence that high-risk perceptions motivate preventive health behaviour such as vaccination $[8,19,22,23]$ and with theoretical evidence that self-focused message will be affectively more salient for those with higher perceptions of risk group membership [21]. Moreover, patients who accepted the vaccination provided reasons more frequently referring to the self-benefits of vaccination, while social-benefit motives were rarely mentioned. In contrast to perceptions of risk group membership, objective risk group membership did not moderate the effect of the messages on vaccine uptake. We invite future research to test our exploratory finding that high risk perceptions dampen the positive effects of social benefit messages.

A majority of our participants had risk misperceptions, most of whom had underestimated their risk. Risk group misperceptions have also been found to be relatively high in a random sample of the US population (34\%), where most misperceptions were similarly due to underestimation (96\%) [33]. These results suggest that understanding the determinants of risk misperceptions in general and risk underestimation in particular are likely to provide crucial insights into vaccination avoidance.

Our simple intervention achieved substantially higher influenza vaccine uptake as compared with high risk reference groups. Factors commonly present in hospitals such as the free provision of the vaccine, the low transaction costs of in-patients, the information provided in the pamphlets, and the presence of a medical authority are likely to have contributed to this outcome. Nevertheless, even when compared with the rate we achieved with our intervention, vaccination rates among high-risk groups in Western countries are substantially higher $(65 \%$ in the US and $74 \%$ in the UK for ages 65 and older in 2011-2012) [3]. Prevalence of anti-vaccination attitudes, fear of side-effects and misplaced self-confidence of patients in Turkey may well explain this discrepancy [41-43].

\section{Limitations of the study}

The difficulty of studying actual vaccination of natural risk groups in the field resulted in four limitations. First, we cannot identify the isolated effect of each message on vaccination uptake due to the lack of a "no intervention" control condition. Given our resources, we opted to maximize the number of observations in the two treatments. Second, description of the mechanism of herd immunity was not provided because our materials were adapted from pamphlets employed by an actual national health service, which refrained from a detailed explanation. Descriptions of herd-immunity have been shown to increase vaccination intentions [11], and it remains to be tested in promoting actual vaccination behavior among patients. Third, we were ethically obliged to present risk group criteria to both treatment groups, which may have resulted in the social-benefit message being mixed with information pertaining to self-benefit. Finally, as we explain in the next paragraph, the moderation of treatment effect by perceptions of risk group membership can be endogenous, although our analysis points to no such confounds. 
We opted to elicit risk group perceptions after the vaccination decisions to avoid biasing of these decisions by the elicitation procedure. However, this design choice opens the measure to possible post hoc rationalizations, in particular, to patients' inaccurate declarations that "they are not at risk" as justifications for their refusal to vaccinate [8]. We did not find evidence for such a confound: among those who were medically assessed to be at high risk, the accuracy of risk perceptions was not significantly different $\left(\chi^{2}\right.$ test; $\left.P=0.729\right)$ between those who refused $(25 \%)$ and accepted vaccination (27\%). Similarly, using post-treatment variables as covariates may bias model estimates if treatments affect these variables. Again, we find no influence of treatments on risk group perceptions ( $\chi^{2}$ test; $P=0.598$ ).

\section{Conclusions}

Public authorities such as the CDC and the European Council prioritize the vaccination of those at most risk against influenza [3, 4]. Our field experiment showed that simple motivational interventions, when implemented in a real clinical setting, can effectively target and substantially increase the vaccination of such high priority groups. We also found that the prosocial vaccination hypothesis does not apply to high-risk groups. These findings do not necessarily contradict previous evidence supporting the hypothesis because social-protection afforded by vaccination can be more valuable than self-protection among the general public who are personally less at risk or among other cultures with stronger prosocial attitudes. Instead, in line with the impetus of the stratified medicine approach [44, 45], our results suggest a significant boundary condition on the prosocial vaccination hypothesis. We therefore suggest that heterogeneity of risk groups and their perceptions should be taken into account when formulating vaccine advocacy policies. In particular, professional communications that aim to promote vaccination among high risk groups may be more effective with an emphasis on vaccination's self-benefit rather than its social benefits. More generally, our study highlights the importance of validating theoretical and laboratory findings in the field, and shows that a stratified approach to behavioural interventions can substantially improve the efficiency of public policies.

\section{Supplementary information}

Supplementary information accompanies this paper at https://doi.org/10. 1186/s12889-020-8246-3.

Additional file 1: Table S1. Responses to questionnaires and their relation to vaccination decisions.

Additional file 2: Dataset.

\section{Abbreviations}

aOR: Adjusted odds ratio; CDC: Centers for Disease Control and Prevention; Cl: Confidence intervals; NHS: National Health Service; OR: Odds ratio; UK: United Kingdom

\section{Acknowledgements}

Not applicable.

\section{Authors' contributions}

$\mathrm{Ol}$ and $\mathrm{BI}$ had the original idea for this research. $\mathrm{Ol}, \mathrm{Bl}, \mathrm{OK}$ and $\mathrm{EF}$ designed the study. Bl collected the data. Ol and OK analysed the data in discussion with $\mathrm{EF}$, which was interpreted by all four authors. Ol drafted the initial manuscript which was revised following suggestions from BI, OK. and E.F. All authors had access to the data and approved the final version.

\section{Funding}

This project was funded by Ministry of Health, Istanbul Education and Research Hospital research grant and by Turkish Science Foundation (TUBITAK) International Research Fellowship Programme 2014-2015 provided to B.I. and by European Union's Horizon 2020 research and innovation programme under the Marie Skłodowska-Curie fellowship number 658186 (https://ec.europa.eu/) to O.I. This work was also supported by the Economic and Social Research Council [grant number ES/P008976/1]. The funders had no involvement in the research.

\section{Availability of data and materials}

All data generated or analysed during this study are included in Additional file 2.

\section{Ethics approval and consent to participate}

The study was approved by the Istanbul Education and Research Hospital Ethics Committee for Clinical Research (No: 855-21/10/2016). Participants gave written informed consent.

Consent for publication

Not applicable.

\section{Competing interests}

The authors declare that they have no competing interests.

\section{Author details}

${ }^{1}$ Centre for Behavioural Economics, Society and Technology (BEST), School of Economics and Finance, Queensland University of Technology (QUT), Brisbane 4000, Australia. ${ }^{2}$ Centre for Decision Research and Experimental Economics (CeDEx), University of Nottingham, Nottingham, UK. ${ }^{3}$ Infectious Diseases and Clinical Microbiology Department, Sisli Hamidiye Etfal Training and Research Hospital, Istanbul, Turkey. ${ }^{4}$ Centre for Clinical Research, The University of Queensland, Herston, Brisbane 4029, Australia. ${ }^{5}$ School of Economics, University of Nottingham, Nottingham NG7 2RD, UK. ${ }^{6}$ School of Psychology, University of Nottingham, Nottingham NG7 2RD, UK.

Received: 2 April 2019 Accepted: 20 January 2020

Published online: 17 February 2020

\section{References}

1. Palache A, Oriol-Mathieu V, Fino M, \& Xydia-Charmanta M. Seasonal influenza vaccine dose distribution in 195 countries (2004-2013): Little progress in estimated global vaccination coverage. Vaccine. 2015;33(42): 5598-5605. https://doi.org/10.1016/j.vaccine.2015.08.082

2. ECDC. European Centre for Disease Prevention and Control. Seasonal influenza vaccination and antiviral use in EU/EEA Member States Overview of vaccine recommendations for 2017-2018 and vaccination coverage rates for 2015-2016 and 2016-2017 influenza sea [Internet]. 2018. Available from: https://ecdc.europa.eu/sites/portal/files/documents/seasonalinfluenza-antiviral-use-2018.pdf

3. Wheelock A, Thomson A, Sevdalis N. Social and psychological factors underlying adult vaccination behavior: lessons from seasonal influenza vaccination in the US and the UK. Expert Rev Vaccines. 2013;12(8):893-901.

4. Galvani AP, Reluga TC, Chapman GB. Long-standing influenza vaccination policy is in accord with individual self-interest but not with the utilitarian optimum. Proc Natl Acad Sci. 2007;104(13):5692-7.

5. Osterholm MT, Kelley NS, Sommer A, Belongia EA. Efficacy and effectiveness of influenza vaccines: a systematic review and meta-analysis. Lancet Infect Dis. 2012;12(1):36-44. 
6. Wheelock A, Miraldo M, Thomson A, Vincent C, Sevdalis N. Evaluating the importance of policy amenable factors in explaining influenza vaccination: a cross-sectional multinational study. BMJ Open. 2017;7(7):e014668.

7. Schmid P, Rauber D, Betsch C, Lidolt G, Denker M-L. Barriers of influenza vaccination intention and behavior-a systematic review of influenza vaccine hesitancy, 2005-2016. PLoS One. 2017;12(1):e0170550.

8. Brewer NT, Chapman GB, Gibbons FX, Gerrard M, McCaul KD, Weinstein ND. Meta-analysis of the relationship between risk perception and health behavior: the example of vaccination. Health Psychol. 2007;26(2):136.

9. Brewer NT, Chapman GB, Rothman AJ, Leask J, Kempe A. Increasing vaccination: putting psychological science into action. Psychol Sci Public Interes. 2017;18(3):149-207.

10. Betsch C, Böhm R, Korn L. Inviting free-riders or appealing to prosocial behavior? Game-theoretical reflections on communicating herd immunity in vaccine advocacy. Health Psychol. 2013;32(9):978.

11. Betsch C, Böhm R, Korn L, Holtmann C. On the benefits of explaining herd immunity in vaccine advocacy. Nat Hum Behav. 2017;1(3):56.

12. Li M, Taylor EG, Atkins KE, Chapman GB, Galvani AP. Stimulating influenza vaccination via prosocial motives. PLoS One. 2016;11(7):e0159780.

13. Brockmann D. Public health: this message must be herd. Nat Hum Behav. 2017;1(3):65

14. Fehr E, Schmidt KM. A theory of fairness, competition, and cooperation. Q J Econ. 1999;114(3):817-68.

15. Henrich J, Boyd R, Bowles S, Camerer C, Fehr E, Gintis H. Foundations of human sociality: economic experiments and ethnographic evidence from fifteen small-scale societies. Oxford: Oxford University Press on Demand; 2004.

16. Boersma GJ, Benthem L, van Beek AP, van Dijk G, Scheurink AJW. Personality, a key factor in personalized medicine? Eur J Pharmacol. 2011; 667(1-3):23-5

17. Israel S, Moffitt TE, Belsky DW, Hancox RJ, Poulton R, Roberts B, et al. Translating personality psychology to help personalize preventive medicine for young adult patients. J Pers Soc Psychol. 2014;106(3):484.

18. Ferguson E, Gallagher L. Message framing with respect to decisions about vaccination: the roles of frame valence, frame method and perceived risk. $\mathrm{Br}$ J Psychol. 2007:98(4):667-80.

19. Rothman AJ, Salovey P. Shaping perceptions to motivate healthy behavior: the role of message framing. Psychol Bull. 1997;121(1):3.

20. Weinstein ND, Kwitel A, McCaul KD, Magnan RE, Gerrard M, Gibbons FX. Risk perceptions: assessment and relationship to influenza vaccination. Health Psychol. 2007;26(2):146

21. Loewenstein GF, Weber EU, Hsee CK, Welch N. Risk as feelings. Psychol Bull. 2001;127(2):267.

22. Vietri JT, Li M, Galvani AP, Chapman GB. Vaccinating to help ourselves and others. Med Decis Mak. 2012;32(3):447-58.

23. Böhm R, Meier NW, Korn L, Betsch C. Behavioural consequences of vaccination recommendations: an experimental analysis. Health Econ. 2017; 26(S3):66-75.

24. Sheeran P, Webb TL. The intention-behavior gap. Soc Personal Psychol Compass. 2016;10(9):503-18.

25. Harris KM, Maurer J, Lurie N. Do people who intend to get a flu shot actually get one? J Gen Intern Med. 2009;24(12):1311.

26. Maurer J. Inspecting the mechanism: a longitudinal analysis of socioeconomic status differences in perceived influenza risks, vaccination intentions, and vaccination behaviors during the 2009-2010 influenza pandemic. Med Decis Mak. 2016;36(7):887-99.

27. Camerer C, Mobbs D. Differences in behavior and brain activity during hypothetical and real choices. Trends Cogn Sci. 2017;21(1):46-56.

28. Andreoni J, Bernheim BD. Social image and the 50-50 norm: a theoretical and experimental analysis of audience effects. Econometrica. 2009;77(5): 1607-36.

29. Harrison GW, List JA. Field experiments. J Econ Lit. 2004;42(4):1009-55.

30. Hertwig R, Ortmann A. Experimental practices in economics: a methodological challenge for psychologists? Behav Brain Sci. 2001;24(3): 383-403.

31. Llupià A, Mena G, Olivé V, Quesada S, Aldea M, Sequera VG, et al. Evaluating influenza vaccination campaigns beyond coverage: a before-after study among health care workers. Am J Infect Control. 2013;41(8):674-8.

32. Rothan-Tondeur M, Filali-Zegzouti Y, Belmin J, Lejeune B, Golmard J-L, de Wazières $B$, et al. Assessment of healthcare worker influenza vaccination program in French geriatric wards: a cluster-randomized controlled trial. Aging Clin Exp Res. 2010;22(5-6):450-5.
33. Brewer NT, Hallman WK. Subjective and objective risk as predictors of influenza vaccination during the vaccine shortage of 2004-2005. Clin Infect Dis. 2006;43(11):1379-86.

34. Chen $\mathrm{H}$, Cohen $\mathrm{P}$, Chen $\mathrm{S}$. How big is a big odds ratio? Interpreting the magnitudes of odds ratios in epidemiological studies. Commun Stat Comput. 2010;39(4):860-4.

35. Rosenthal JA. Qualitative descriptors of strength of association and effect size. J Soc Serv Res. 1996;21(4):37-59.

36. Derks D, Bos AER, Von Grumbkow J. Emoticons in computer-mediated communication: social motives and social context. CyberPsychology Behav. 2008:11(1):99-101.

37. Lo S-K. The nonverbal communication functions of emoticons in computermediated communication. CyberPsychology Behav. 2008;11(5):595-7.

38. Thaler RH, Sunstein CR. Nudge: Improving decisions about health, wealth, and happiness. New Haven: Yale University Press; 2008.

39. Simmons JP, Nelson LD, Simonsohn U. False-positive psychology: undisclosed flexibility in data collection and analysis allows presenting anything as significant. Psychol Sci. 2011;22(11):1359-66.

40. Ciblak MA, Platformu G. Influenza vaccination in Turkey: prevalence of risk groups, current vaccination status, factors influencing vaccine uptake and steps taken to increase vaccination rate. Vaccine. 2013;31(3):518-23.

41. Buyuktiryaki B, Soyer OU, Erkocoglu M, Dogan A, Azkur D, Kocabas CN, et al. What a pandemic teaches us about vaccination attitudes of parents of children with asthma. Vaccine. 2014;32(20):2275-80.

42. Akan H, Gurol Y, Izbirak G, Ozdatlı S, Yilmaz G, Vitrinel A, et al. Knowledge and attitudes of university students toward pandemic influenza: a crosssectional study from Turkey. BMC Public Health. 2010;10(1):413.

43. Arda B, Durusoy R, Yamazhan T, Sipahi OR, Taşbakan M, Pullukçu H, et al. Did the pandemic have an impact on influenza vaccination attitude? A survey among health care workers. BMC Infect Dis. 2011;11(1):87.

44. Hingorani AD, van der Windt DA, Riley RD, Abrams K, Moons KGM, Steyerberg EW, et al. Prognosis research strategy (PROGRESS) 4: stratified medicine research. Bmj. 2013:346:e5793.

45. Trusheim MR, Berndt ER, Douglas FL. Stratified medicine: strategic and economic implications of combining drugs and clinical biomarkers. Nat Rev Drug Discov. 2007;6(4):287

\section{Publisher's Note}

Springer Nature remains neutral with regard to jurisdictional claims in published maps and institutional affiliations.

\section{Ready to submit your research? Choose BMC and benefit from:}

- fast, convenient online submission

- thorough peer review by experienced researchers in your field

- rapid publication on acceptance

- support for research data, including large and complex data types

- gold Open Access which fosters wider collaboration and increased citations

- maximum visibility for your research: over $100 \mathrm{M}$ website views per year

At $\mathrm{BMC}$, research is always in progress.

Learn more biomedcentral.com/submissions 